\title{
IMPORTÂNCIA DO CONSENTIMENTO INFORMADO NA ONCOLOGIA
}

\author{
Ayla Martins Ramos Mourthé ${ }^{1}$, Débora Rosmaninho Coutinho de Melo ${ }^{1}$, Paula Fontes \\ Passalini Gonçalves ${ }^{1}$, Rachel Boechat Cabral $^{1} \&$ Hildeliza Lacerda Tinoco Boechat Cabral ${ }^{2 *}$ \\ http://dx.doi.org/10.18571/acbm.005
}

\section{RESUMO}

A partir da Declaração Universal dos Direitos Humanos todos os estados democráticos incluem em suas constituições o princípio da dignidade da pessoa humana. No Brasil não foi diferente. Este princípio, alçado à categoria de valor pelo ordenamento jurídico brasileiro passa a reclamar uma tutela dos direitos relativos à pessoa - os direitos da personalidade muito exigente. Nessa esteira, o presente artigo objetiva demonstrar que o consentimento informado ganha especial relevo, devendo o médico sempre explicar à pessoa a respeito do tratamento ou cirurgia, com detalhes para que esta possa consentir na atuação em sua esfera psicofísica. Pretendeu-se assinalar a importância do consentimento informado na atual perspectiva da proteção à dignidade humana e os direitos a ela inerentes, principalmente na oncologia, casos em que há doenças incuráveis ou de rara probabilidade de cura.

Palavras-chave: Dignidade da pessoa humana, dever de informação, consentimento, oncologia.

\section{RESUMEN}

A partir de la Declaración Universal de los Derechos Humanos todos los estados democráticos incluyen en sus constituciones el principio de la dignidad de la persona humana. En Brasil no fue diferente. Este principio, alzado a la categoría de valor por el ordenamiento jurídico brasileño se pone a reclamar una tutela de los derechos relativos a la persona - los derechos de la personalidad - muy exigente. En esa tabla, el presente artículo objetiva demostrar que el consentimiento informado gaña especial relevo, debiendo el médico siempre explicar a la persona a respecto de lo tratamiento o cirugía, con detalles para que este pueda consentir en la actuación en su esfera psicofísica. Se pretendió señalar la importancia del consentimiento informado bajo la actual perspectiva de la protección de la dignidad humana y los derechos a ella inherentes, principalmente en la oncología, casos en que hay enfermedades incurables o de rara esperanza de cura.

Palabras-llave: Dignidad de la persona humana; deber de información; consentimiento; oncología

1 Acadêmica do Curso de Medicina da Universidade Iguaçu

2 Professora do Curso de Graduação em Direito

*Autor para correspondência. hildeboechat@ gmail.com 
Ayla Martins Ramos Mourthé, Débora Rosmaninho Coutinho de Melo, Paula Fontes Passalini Gonçalves, Rachel Boechat Cabral \&

Hildeliza Lacerda Tinoco Boechat Cabral

Importância do Consentimento Informado na Oncologia

\section{INTRODUÇÃO}

A ciência médica caminha a largos passos como também evoluem os direitos da personalidade. O exercício da Medicina sempre foi de grande relevância social e permeado por diversificadas formas de deveres de cuidado principalmente porque tem por objetos os bens jurídicos vida e saúde, aqueles de primeira grandeza, a gozarem de maior prestígio no ordenamento jurídico, por se tratarem de direitos referentes à pessoa e à sua dignidade.

Começa-se a compreender que o ser humano deixa a condição de paciente, palavra que possui uma carga semântica que sugere certa passividade, para se transformar em agente de suas decisões, por isso passa-se a denominá-lo simplesmente de pessoa.

Com a crescente valorização dos direitos da personalidade, o direito à informação vem crescendo e compelindo as ciências que trabalham com a pessoa humana a cumprir o dever de informar, uma vez que esta passa a ter direito à informação e à livre manifestação de consentimento para atuação em sua esfera pessoal.

Assim, o Consentimento Informado ganha especial reconhecimento como direito da personalidade, de forma que passa a ser uma prática cotidiana do profissional da Medicina explicar à pessoa quais são as condutas a serem praticadas em sua esfera pessoal, para depois tomar o seu consentimento para essa intervenção.

É o que se pretende demonstrar neste artigo que visa despertar a comunidade acadêmica para a relevância do Consentimento Informado, especificamente em relação à pessoa portadora de tumor maligno, que geralmente apresenta quadro clínico com uma circunstância agravante do ponto de vista emocional, qual seja, a incerta possibilidade de cura.

\section{O PRINCÍPIO DA DIGNIDADE HUMANA E O DEVER DE INFORMAÇÃO}

A partir do momento pós-guerra, constatadas as atrocidades ocorridas, principalmente no que respeita à dizimação dos judeus pelos alemães, inclusive usando-os para experimentações de medicamentos e toda forma de subjugação do ser humano, surge a Declaração Universal dos Direitos Humanos, marco a partir do qual todas as constituições pós-modernas passam a inserir em seus textos o princípio da dignidade da pessoa humana.

\subsection{Princípio da Dignidade Humana e Direitos Existenciais}

Com o movimento de valorização da pessoa, que teve início na era cristã e ganhou expressão a partir do pós-guerra com a Declaração Universal dos Direitos Humanos, como já comentado, consagrou-se o Princípio da Dignidade da Pessoa Humana. No Brasil não, a Constituição Federal de 1988, colocou a dignidade da pessoa humana como um dos fundamentos da República Federativa do Brasil, logo no art. $1^{\circ}$, III, o que lhe confere precedência não só topográfica, como interpretativa (ROSENVALD, 2007, p.35), devendo ser analisado com preferência sobre qualquer outro, elevando o princípio em comento à categoria de valor, transformando-o em axioma a permear todas as relações sociais e jurídicas neste Estado Democrático de Direito.

Assim, passam os direitos existenciais - aqueles decorrentes da dignidade da pessoa humana a gozar de extrema importância e proteção legal, expressivamente em relação às ciências que cuidam da pessoa, nessa qualidade que somente aos seres humanos é inerente.

Nesse contexto, passa o médico a adotar, em relação a seu paciente, condutas que garantam o respeito aos direitos da personalidade. $\mathrm{O}$ que ocorreu é que o paciente transpôs a linha de mero espectador das intervenções em sua esfera psicofísica, passando a sujeito capaz de influenciar a atuação profissional através do exercício de seus direitos da personalidade, 
principalmente, a autonomia existencial - que permite à pessoa a decidir, a se conduzir às escolhas rumo ao seu futuro. $\mathrm{O}$ paciente é elevado à qualidade de sujeito, passando a ser agente de sua própria vontade e conquista o direito à decisão de se submeter ou não a certo procedimento terapêutico ou cirúrgico, decisão esta devidamente dialogada pelo médico.

\subsection{O Dever de Informar}

Segundo Cavalieri Filho (2008, p. 83-84) o dever de informar é consequência do direito à informação que tem a pessoa, previsto no art. $6^{\circ}$, III do Código de Defesa do Consumidor. Isso porque entre médico e paciente se estabelece um contrato que é regido por esse código, pois há por um lado, o médico, prestador de um serviço, e, por outro, a pessoa que é o consumidor, sendo que entre ambas, existe um objeto do contrato que é o tratamento ou cirurgia.

Cumprindo o dever de informação, determina o Código de Ética Médica, que delineia a atuação ética no exercício da medicina, em seu art. 34: é vedado ao médico:

Deixar de informar ao paciente o diagnóstico, o prognóstico, os riscos e os objetivos do tratamento, salvo quando a comunicação direta possa lhe provocar dano, devendo, nesse caso, fazer a comunicação a seu representante legal.

O dever de informação é abrangente, compreendendo a conscientização de possíveis riscos, possibilidades, probabilidades, modalidades de tratamento terapêutico ou cirúrgico, inclusive a iatrogenia. Compreende ainda o dever de aconselhar, o que se deve ao fato de ser o médico o detentor do conhecimento técnico e científico indispensável à cognição da condição geral do paciente, além de ser a pessoa de confiança que o próprio paciente elegeu para se tratar.

Nesse sentido, para que tal decisão seja segura, necessita o médico informar devidamente o paciente, sobre seu quadro clínico, suas reais possibilidades e os riscos aos quais irá se submeter, e, em seguida, extrair o seu consentimento para a atuação em sua esfera pessoal. Para tanto, indispensável que a relação médico-paciente seja baseada no diálogo e no princípio da solidariedade; e que seja também observada a boa-fé objetiva, que se materializa em condutas capazes de atender às expectativas do paciente em relação a valores como lealdade, confiança, segurança e transparência.

Segundo Cavalieri Filho (2008, p. 83-84) a informação deve preencher três requisitos: adequação, suficiência e veracidade. Significa dizer que a obrigação de informar deve ser cumprida quantitativa e qualitativamente, devendo o médico fornecer o maior número possível de informações e que sejam apresentadas mediante clareza, objetividade e em linguagem adequada à fácil intelecção por parte do paciente, conforme seu grau de instrução.

\section{O CONSENTIMENTO INFORMADO}

A doutrina do consentimento informado recebeu influência norte-americana, onde a expressão informed consent surge em uma decisão do Tribunal da Califórnia, 1957, segundo Kifouri Neto (2002, p. 282). Em seguida, segundo João Vaz Rodrigues apud Kifouri Neto (2002, p. 282), em Portugal (Canotilho e Vital Moreira) e Itália (Código de Deontologia de 1995) passam a reconhecer o direito à autodeterminação da pessoa. No Brasil, ganha repercussão a partir da Constituição Federal de 1988, “constituição cidadã”[1], sob influência do movimento de constitucionalização do Direito Civil que propõe uma interpretação dos institutos de Direito Civil à luz dos princípios constitucionais, passa-se a valorizar a pessoa, sua existência e os direitos a ela inerentes, através da cláusula geral, aberta e principiológica[5] dos direitos da personalidade contida no art. $1^{\circ}$, III da Lei Maior. 
Mas, afinal, o que é Consentimento Informado? No caso específico da relação jurídica médico-paciente, o consentimento é o ato pelo qual o segundo autoriza o primeiro a realizar determinada atuação em sua esfera psicofísica, com o propósito de interferir positivamente de modo a melhorar suas condições de saúde. Corresponde ao aval que a pessoa presta ao médico, para o procedimento terapêutico ou cirúrgico que, a seu ver, se faz necessário. Consentimento é uma escolha voluntária, que surge da reflexão baseada nas informações do médico a respeito do quadro clínico e da intervenção a ser realizada.

Antes, porém, cumpre ao médico o dever de informação, fornecendo todos os subsídios capazes de embasar uma decisão consciente, esclarecendo as possíveis dúvidas do paciente, para em seguida obter o consentimento para proceder àquela determinada conduta.

O Consentimento Informado é materializado em um documento ao qual se denomina Termo de Consentimento Informado, que deve ser datado e assinado por ambas as partes médico e a pessoa contratante - contendo a especificação do procedimento que será realizado na esfera pessoal do segundo, sendo a escrita a forma ideal, uma vez que o consentimento somente verbal precisaria ser testemunhado para ter valor em um futuro processo judicial.

Em qualquer das formas, tanto na escrita como na verbal, serão sempre conjugadas, uma vez que as explicações são fornecidas através de minucioso diálogo, através do qual o médico irá perguntar se o paciente compreendeu o que foi explicado e poderá elucidar possíveis dúvidas.

O Código de Ética Médica encontra-se em perfeita sintonia, segundo o que se pode apreender dos seguintes artigos:

É vedado ao médico:

Art. 22. Deixar de obter consentimento do paciente ou de seu representante legal após esclarecê-lo sobre o procedimento a ser realizado, salvo em caso de risco iminente de morte.

Art. 23. Tratar o ser humano sem civilidade ou consideração, desrespeitar sua dignidade ou discriminá-lo de qualquer forma ou sob qualquer pretexto.

Art. 24. Deixar de garantir ao paciente o exercício do direito de decidir livremente sobre sua pessoa ou seu bem-estar, bem como exercer sua autoridade para limitá-lo.

médico:

O mesmo Código protege a livre manifestação de vontade da pessoa, sendo vedado ao

Art. 26. Deixar de respeitar a vontade de qualquer pessoa, considerada capaz física e mentalmente, em greve de fome, ou alimentá-la compulsoriamente, devendo cientificá-la das prováveis complicações do jejum prolongado e, na hipótese de risco iminente de morte, tratá-la.

Percebe-se que é importante ainda, pelo que diz o art, 26 que a pessoa precisa ser respeitada até quando em greve de fome. Isso significa que ela será protegida e respeitada em todas as circunstâncias, podendo o médico agir de acordo com sua consciência somente em casos extremos como o risco de morte.

É necessário lembrar que o descumprimento do dever de informar enseja responsabilização civil, sendo, por si só, a ausência da informação ou de consentimento, lesão autônoma, danosa e passível de indenização, igualmente, a informação incorreta (LORENZETTI apud KIFOURI NETO, p. 302). Lesão autônoma é aquela capaz de por si só responsabilizar civilmente. Além de ser um direito do paciente, o Consentimento Informado se constitui importante garantia do médico, assim como o prontuário, é um documento essencial. Ambos podem se tornar poderosos instrumentos de defesa em juízo, podendo representar importante meio de prova, afastando a responsabilidade civil do profissional no que tange ao cumprimento do dever de informação. 


\section{O CONSENTIMENTO INFORMADO EM ONCOLOGIA}

\subsection{Lineamentos Conceituais de Oncologia}

Primeiramente há que se ponderar o conceito da expressão Oncologia se origina da palavra grega: oykos, que significa volume, tumor. Sendo assim a oncologia é a especialidade médica responsável pelo estudo dos tumores (neoplasias), que podem ser benignos ou malignos. Esse ramo da medicina tem por objetivo estudar o desenvolvimento do tumor no organismo de cada paciente, procurando obter o tratamento específico para cada indivíduo.

O principal objetivo da oncologia é proporcionar uma melhora na qualidade de vida do paciente. $\mathrm{O}$ oncologista além de tratar a patologia em si, deve dar um amparo psicológico fornecendo todas as informações que lhe são devidas, a fim de que o paciente tenha um real entendimento da sua condição. Vale ainda ressaltar que o médico precisa compreender a fraqueza emocional que o paciente está vivendo, portanto deve apoiá-lo, respeitá-lo e compreendê-lo acima de tudo.

Como já foi dito o tratamento oncológico é sempre individualizado, com base nas necessidades e opções terapêuticas de cada paciente. Esse tratamento pode ser tanto curativo, quando objetiva curar o paciente; ou paliativo, no qual o intuito é amenizar o sofrimento do paciente, melhorando sua qualidade de vida.

Não havendo a possibilidade de cura para o tumor,o médico oncologista tem a função de conduzir o paciente ao tratamento paliativo, no qual não haverá uma esperança de cura da enfermidade, mas sim a utilização de medidas terapêuticas a fim de melhorar a sobrevida do paciente, aliviando seu sofrimento e minimizando a sua dor.

\subsection{O Consentimento Informado aplicado às pessoas portadoras de tumores malignos}

Nos casos de pessoas portadoras de tumores malignos, o consentimento informado deve ser observado de forma peculiar, pois o médico deve procurar sempre a maneira menos gravosa de conversar sobre o assunto, dialogar e se colocar à disposição para sanar eventuais dúvidas.

Em se tratando de pessoa capaz, lúcida e apta a praticar os demais atos da vida, o médico pode e deve informá-la diretamente, através de uma conversa que possa causar menos

Essa informação fornecida diretamente à pessoa portadora em razão dos direitos da personalidade, decorrentes do respeito ao princípio da dignidade da pessoa humana.

Quando a pessoa, embora capaz, não se mostra em condições psicológicas e emocionais de ser informada, ou quando não possui capacidade mental para uma conversa franca e sadia, o médico, e somente nesses casos, deve informar ao representante legal.

A grande questão que se levanta e ainda sem uma resposta conclusiva é a seguinte: se a pessoa nunca está acompanhada de outra e parece não ter representante legal e diz ao médico que deseja não ser informada sobre a enfermidade, que prefere não saber sobre a gravidade, nem efeitos colaterais dos medicamentos, nem quanto aos atos futuros a serem praticados. Nesse caso, estaria o médico desobrigado do dever de informar?

A grande maioria das pessoas que descobrem ser portadoras de tumores malignos, geralmente precisam de apoio da família e quase sempre comparecem acompanhadas por familiares, caso em que o médico deve, na dúvida se ela foi capaz de compreender a complexidade da questão em que se encontra, explicar o diagnóstico, medicamentos e analisar o prognóstico na presença deste que a acompanha, até por uma questão de segurança, sem abrir mão de redigir o Termo de Consentimento Informado, que deve ser datado e por ambas as partes assinado.

\section{CONCLUSÃo}


$\mathrm{Na}$ atual visão dos direitos da personalidade e em razão do prestígio da dignidade da pessoa humana no ordenamento jurídico, o dever de informação deve ser cumprido pelo médico, pois a pessoa tem direito à informação.

Então toda pessoa tem direito de saber os detalhes sobre o tratamento ou cirurgia que o médico irá realizar em sua esfera pessoal. Nesta esteira, o Consentimento Informado ganha bastante relevância porque é necessário que a pessoa consinta nessa intervenção, após as informações fornecidas pelo médico.

O documento que exterioriza essa informação e consequente consentimento para a atuação médica é o Termo de Consentimento Informado, que no caso dos pacientes portadores de tumores malignos se reveste de capital importância, principalmente em função das particularidades de cada caso.

No caso específico da Oncologia, o dever de informar e o assentimento da pessoa para o tratamento e/ou cirurgia são de grande relevância, uma vez que ela mesma é quem deve decidir sobre que atuações em seu próprio corpo devem ser realizadas a fim de erradicar ou minorar os efeitos dos tumores malignos.

Embora a regra seja que a informação possa e deva ser fornecida diretamente à pessoa interessada, é necessário frisar que algumas das pessoas portadoras de tumores malignos não podem ser informados diretamente, por não estarem em condições psicoemocionais que o permitam, caso em que a informação e o consentimento terão como destinatário o responsável legal.

\section{NOTAS E REFERÊNCIAS:}

BOECHAT CABRAL, Hildeliza Lacerda Tinoco. Indispensabilidade do consentimento informado no exercício da atividade médica. Em 2009. Disponível em www.laboratoriojuridico.com.br

CAVALIERI FILHO, Sergio. Programa de Direito do Consumidor. São Paulo: Atlas, 2008.

KIFOURI NETO, Miguel. Culpa Médica e Ônus da Prova. Revista dos Tribunais. São Paulo: 2002.

LORENZETTI apud KIFOURI NETO, Miguel. Culpa Médica e ônus da prova. São Paulo: Revista dos Tribunais, 2002

ROSENVALD, Nelson. Dignidade Humana e Boa-Fé no Código Civil. Saraiva. 1ed. São Paulo: 2007.

VAZ RODRIGUES, João apud KIFOURI NETO, Miguel . Culpa Médica e Ônus da Prova. Revista dos Tribunais. São Paulo: 2002, p. 282-284.

[1] Expressão criada por Ulysses Guimarães, Presidente da Assembléia Constituinte, para designar a nova Constituição pela relevância dos valores pessoais nela contidos, em 1988. 